\title{
Are we responsible for the epigenetic changes we pass on to our offspring?
}

\section{Marc-André Sirard, Ph.D.}

\section{Chaire de Recherche du Canada en Génomique, Département des Sciences Animales, Université Laval, Québec, Canada, G1V 0A6 Email: Marc-Andre.Sirard@fsaa.ulaval.ca}

Darwin was the father of genetic determinism as he demonstrated the effect of the environment on the selection of individuals to be able to transmit their genes to the next generation. The natural selection takes thousands of years to change a character in a whole population while Lamarck was rather under the impression that the environment could have an immediate impact on the traits of the next generation and ended up being ridiculed when genetic experiments supported Darwin's views. As predicted by his daughter and inscribed on his tomb: "La postérité vous admirera, elle vous vengera, mon père" (time will bring revenge and admiration) Lamarck could well be avenged by recent discoveries. Indeed, it is now increasingly recognized that the environment of the parent has an impact on the next generation through a mechanism called epigenetics. Epigenetics modifies the labelling of the DNA without changing the genetic sequence and can be transmitted through the eggs and sperm. Epigenetics is also the mechanism by which all of our cells have the same genome but different functions. Most of the epigenetic programming occurs during embryonic and fetal development, however aberrant alterations also occur in many diseases including cancers.

The recent review in Science by Sarah Robertson's research group ${ }^{1}$ provides a long list of evidence that parents, mothers and fathers alike, in all mammals tested, influence the future phenotype(health) of their children with more than the genes they transmit. It has been observed that both over- and under-nutrition in parents create a propensity for accumulating fat in the offspring. While it might seem bizarre that two opposite conditions cause the same phenotype, indeed excess weight gain and weight loss can indeed lead to the same consequence: a release of fatty acids/triglyceride in the blood caused by excess eating in one case or by their release of fatty acids from fat reserves during starvation. The result is a tendency for the next generation to store more calories. This phenomenon would represent rapid adaptation to variable calories availability between seasons and some types of sugar associated with fall harvest such as fructose, would be a signal for energy storage. In our modern society where food is abundant all year round, such programmed responses generate insulin resistance and rapid fat uptake for storage, leading to obesity, diabetes and cardio-metabolic diseases.

If parental environment and lifestyle affect their unborn offspring, this begs the question: "who is responsible? Our ancestors, our parents, society, big companies adding fructose and/or fat in our food or scientific ignorance? Admittedly, individual freedom allows everyone to eat what they want, even if some may die more rapidly because of their unhealthy diet. But what about the harm we cause others such as our children? I would argue, our knowledge of epigenetics necessitates the introduction of a new regulatory framework for society which must protect the innocent and in this case future generations against harm caused by the parents' lifestyle. To implement such a framework involves explaining the scientific basis of the phenomenon and informing future parents through proper communication programs and better food labelling. Who is responsible? We as scientists and we as parents!

\section{References}

1. Lane M, Robker RL, Robertson SA. Parenting from before conception. Science. 2014 Aug 15;345(6198):756-60.

Dr. Sirard holds a Canadian Research Chair in genomics applied to reproduction since 2001 . He has spent most of his carrier in the field of animal and human reproduction, especially in vitro fertilization before developing an expertise in genomics and more recently epigenomics. Through the Embryogene network his team have develop transcriptomic and epigenomic platforms to study minute samples as gametes and embryos. 